\title{
Integrating BIPV during Early Stages of Building Design
}

\author{
Martin Kaftan ${ }^{1}$, Sebastian Sautter ${ }^{2}$, Bernhard Kubicek ${ }^{3}$ \\ ${ }^{1}$ TU Brno, Faculty of Architecture ${ }^{2}$ TU Graz ${ }^{3}$ Austrian Institute of Technology \\ ${ }^{1}$ kaftan@fa.vutbr.cz ${ }^{2}$ sautter@tugraz.at \\ 33brnhard.kubicek@ait.ac.at
}

In the quest to achieve the ambitious climate and clean energy targets the broad implementation of Integrated Photovoltaics (BIPV) is one of the keys.

Photovoltaic (PV) modules can be installed above or on current roofing or traditional wall structures. In addition, BIPV devices substitute the skin of the exterior construction frame, i.e. the weather screen, thus simultaneously acting as both a climate screen and an energy producing source. However, while the integral planning strategy to building projects promotes the effective execution of $B I P V$, the limitation lies in the absence of both instruments and easy-to-use planning aid guidelines, particularly by non-PV experts in the early design stage. This study presents computational methods that help to quickly analyze the BIPV potential for a given building project and to suggest the optimal economical amount and location of the panels based on the building's energy demand profile.

Keywords: building integrated photovoltaic (BIPV), integral planning, design rules, simplified models, machine learning

\section{INTRODUCTION}

A comprehensive planning guideline is needed during the building planning in order to effectively introduce Building-Integrated Photovoltaics (BIPV). The area-wide application of BIPV is essential according to the definitions of the European Union's Climate Targets (2009, 2011 and 2015). At the same time, the European Building Directive [1] provides for the mandatory application of BIPV or comparable measures to generate renewable energy. These regulations require significant efforts in terms of information accessibility and process simplification for BIPV to be considered in the building and urban district planning. There is, however, an absence of both instruments and a set of guidelines that can be readily implemented to help those designers who are not ex- perienced in PV in particular at the early stage of design. For example one of the important aspects is the economic feasibility of the BIPV installment given its expected lifetime 20-25 years (Ritzen 2017). The advantages of BIPV systems are that PV can cover more construction surfaces and replace some of the traditional building components (e.g. facade cladding), but while BIPV can fully cover the surface of the building, only partial coverage would actually make sense in terms of reasonable payback time (Perez 2012). The most common way is the integration of PV into rooftops. However, even though the vertical facade surface receive less radiation than rooftops, the facade can still significantly contribute to the electricity production, especially in some cases of building demand profiles (e.g. constant high energy demand or 
high demand in the morning) .

The simplification is the key also in terms of approach to digital modeling where relatively simple parametric model is enough to analyze its solar potential within its urban location and placement of PV panels. This enables fast massing studies and quick design changes.

This presented work was part of the applied research called VITALITY, which searched to design rules for the early planning phase of buildingintegrated photovoltaics.

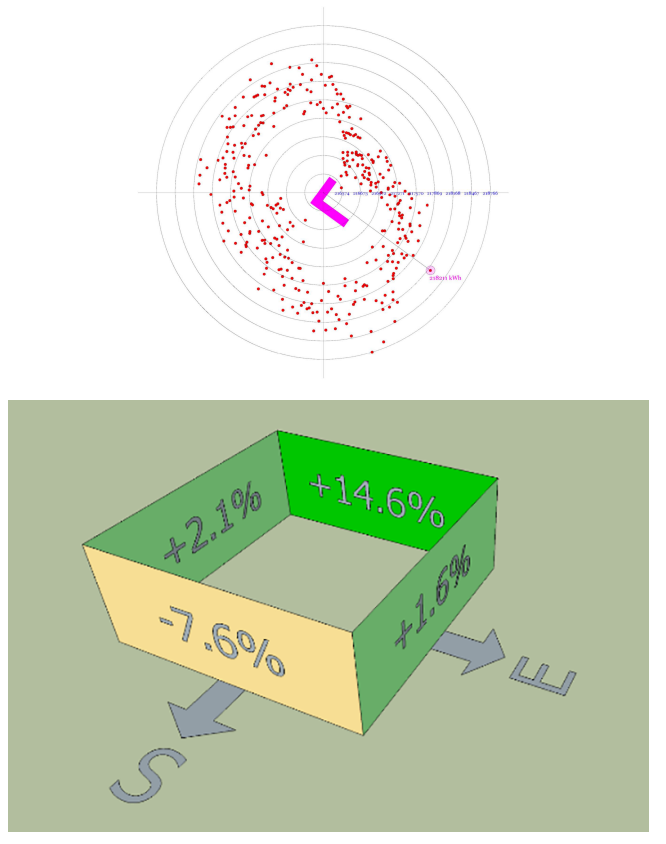

\section{METHODS}

The following methods deal with the development of instruments for an integrative planning process. The purpose of the developed tools is to quickly indicate the solar potential of the building. Moreover, the optimal placement of the BIPV is suggested with providing information about the cost and investment return (payback time). All the tools are developed for parametric environment, therefore, coupled with other simulation tools such as thermal performance and lighting analysis provide planning information in order to avoid design flaws already in the early design stage that could be later difficult to repair (Kaf$\tan 2016$ ).

\section{Solar potential}

For initial studies and visualizations of the solar potentials on building's surface with regards to its orientation was set up an interactive tool. In order to visualize the solar potential for different building's orientations, the building is rotated in $1^{\circ}$ steps. The tool evaluates the results; each rotation step is mapped on a radial graph and presents the solar roof/façade potential ratio and energy demand of the building (Fig. 1).

\section{PV Yield}

This method was introduced to the project by the collaborating team from the Austrian Institute of Technology. The method implements a simplified calculation method of PV energy yield which significantly cuts down the calculation time. As the focus of the project is on building integrated $\mathrm{PV}$, the irradiance on the surface of the building envelope is the same as the irradiance in plane of the PV modules (EPV). The module temperature $(\nabla \mathrm{M})$ is calculated as a function of irradiation, ambient temperature and installation situation. Standard characteristic values for different PV components, like module efficiency (nPV), inverter efficiency ( $\eta \mathrm{INV}$ ) and temperature coefficient (aP) are used to respect the energy losses in the yield calculation. Finally, the PV yield is calculated as follows:

$$
P V_{Y i e l d}=E_{P V} \eta_{P V} \eta_{I n v}\left(1+\alpha_{P}\left(\vartheta_{M}-25^{\circ} C\right)\right)
$$

To validate the simplified calculation method, a comparison of the yearly energy yield for north, east, south and west façade with the commercial $\mathrm{PV}^{*} \mathrm{SOL}$ simulation tool was done (Fig. 2). On the east
Figure 1 Interactive navigation to building's solar potential.

Figure 2

Validation of the simplified yield calculation with the commercial simulation tool $\mathrm{PV} * \mathrm{SOL}$. 
Figure 3

In green, the load

demand of a

building is shown

over three days.

The PV (violet) only produces under the day. If the PV production is below the load profile, it can be valued by $0,2 € /$ kWh. Any surplus, e.g. in the afternoon of the second day, is only valued by the grid feed-in tariff.

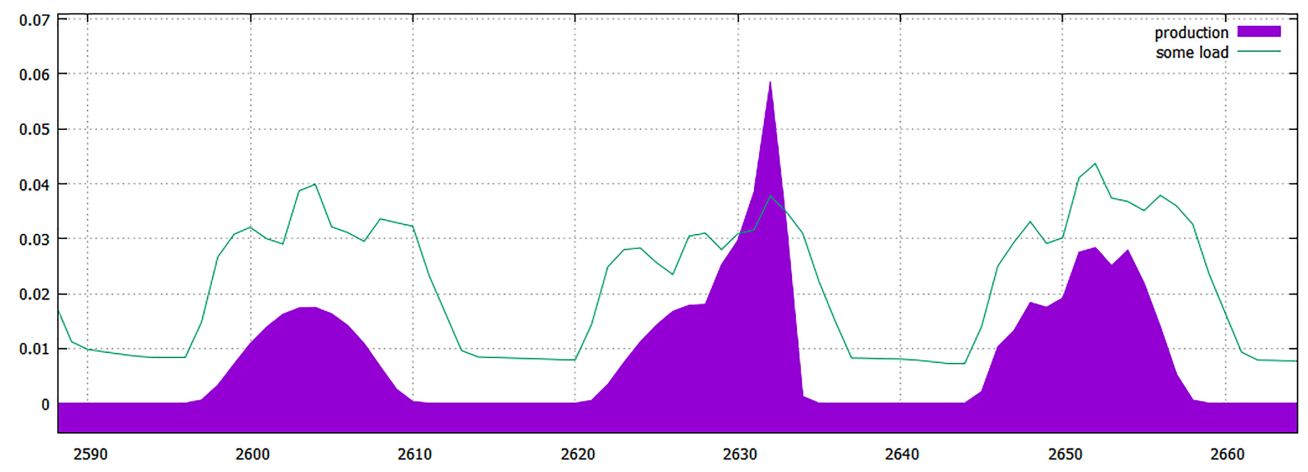

and west façade, the yearly energy yield simulated is about $2 \%$ higher than the calculated yield, whereas on the south façade it is about $7 \%$ less. Most significant deviations occur on the north facade with more than $14 \%$.

The programmed tool based on this method has drop down input menus. First menu enables to select the type of the photovoltaics module. The main distinguishing is between the mounting types (roof vs. façade) and ventilation. The second menu enables to select the type of PV cell (e.g. monocrystalline, polycrystalline, etc.) The third input are the hourly values of the solar irradiance $(\mathrm{w} / \mathrm{m} 2)$ for each panel. The hourly inputs for wind $(\mathrm{m} / \mathrm{s})$ and temperature $(\mathrm{C})$ come from the weather data e.g. from the Energy+ database.

\section{Payback time}

The decision of whether to integrate BIPV is very often also based on its economic value. Therefore, it is necessary to correctly calculate the time for the return of investment - the payback time. The locally produced electricity, measured in Watt hours [Wh], has under the current legislation varying value depending if it is fed into the external power grid, or consumed locally. Self-consumption is economically as valuable as grid outtake and includes not only the raw value of electricity ( $0.06 € / \mathrm{kWh}$ ) but also taxes, grid transportation taxes, and the markup of the ex- ternal energy company, summing to typically ( 0.2 $€ / \mathrm{kWh})$. Hence, if one were to choose how much PV should be installed, the actually temporal electric energy demand profile of the building should be regarded ("optimization of self-consumption").

Therefore, the developed tool compares the electricity production of the allocated roof + façade surfaces with the electric energy demand od the building. For each hour is calculated the order of the panels according to the corresponding hourly electricity production. In addition, if the PV panel during the hour based on the order still contributes to the building's energy demand, then the PV's produced electricity is converted to income with price as if buying from the energy supplier (from the grid). If the panel's production already exceeded the building's demand for the hour, it is converted to income with price as if selling it to the energy supplier (to the grid). The sum of the hourly incomes gives the annual income for each panel and by providing the required average payback time are selected only PV panels which satisfy this threshold. In addition, if the threshold for the maximum available roof area is less than $100 \%$, the panels are further sorted and selected based on this threshold. The profile of the electric energy demand of the building that will be still needed in addition to the BIPV production is also calculated. 

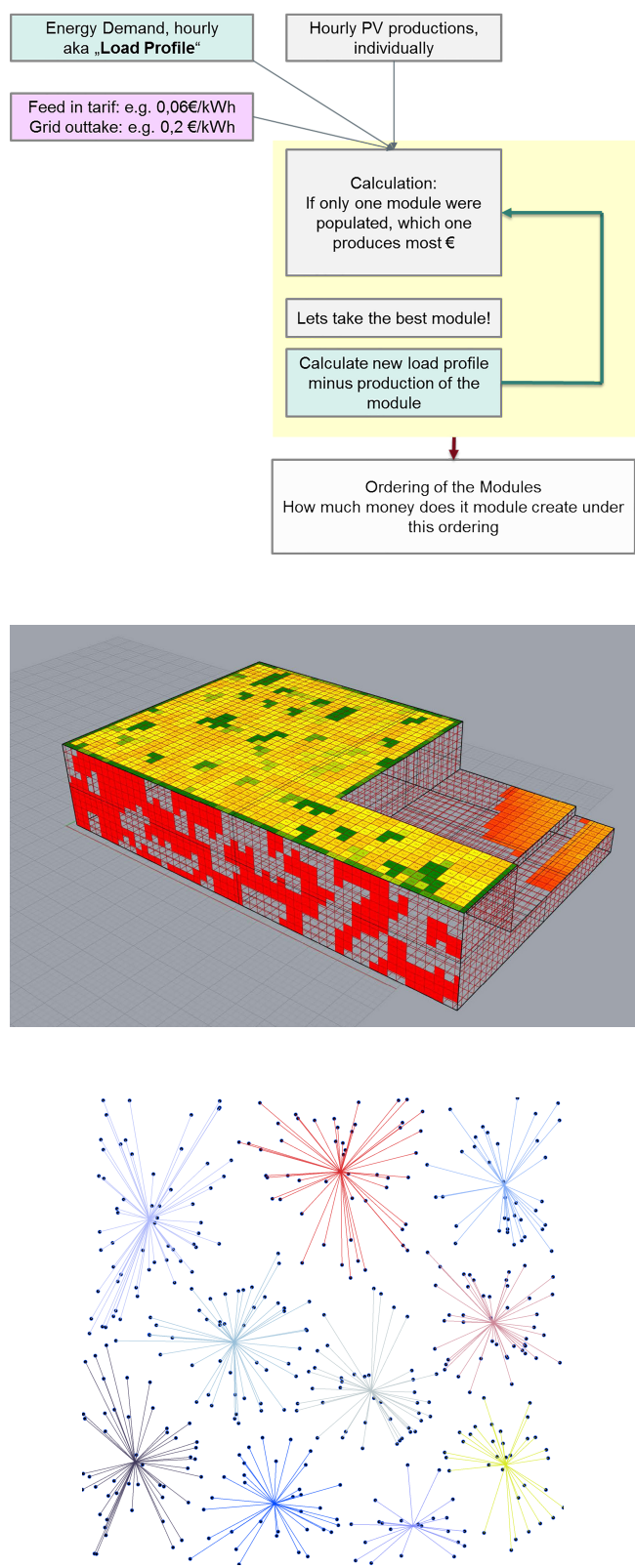

\section{Clustering}

However, the previously described method holds one flaw; the algorithm does not take in account any clustering of the panels. Therefore, the results, even though correct in terms of PV panels amount and orientation, appear unrealistically scattered over the building (Fig. 5). This is due to the ray tracing-based method of the radiance calculation which has some deviation error for each panel even though the unshaded light condition would be the same for all panels on the same plane. Therefore, to solve this issue, and also to speed up the computational process that otherwise increases exponentially with the amount of PV panels, the algorithm called k-means was implemented.

$\mathrm{K}$-means in one of the simplest unsupervised machine learning algorithms. The objective of kmeans is to group similar data points together and find hidden patterns. In order to find the objective the method searches for a predefined number of clusters in a dataset (Steinbach 2004). This target number defines the amount of needed centroids in the data, which represent the centers of the clusters (Fig. 6). Starting with random positions the algorithm data mines iteratively and repositions the centers. K-means stops either when the centroids have stabilized, so there is no change in their values or when the defined number of iterations has been performed. We programed our k-means algorithm for four dimensional space (4D). The first three dimensions were given by the $X Y Z$ coordinates of centroid of each panel. The annual radiation of the panels provided the fourth dimension. To determine the centroid of each cluster was used squared Euclidian distance (formula).

The information about the clustering were fed to the payback time algorithm. Now the method after finding the best performing panel continues the search inside the cluster to which this panel belongs. After all the panels in the cluster are used it seeks the next best performing panel and repeats the ordering of the panels by payback time inside this cluster. This process is repeated cluster by cluster until the thresh-
Figure 4

The algorithm to iteratively find a good placement priority for the PV modules.

Figure 5

Scattered result of BIPV placement based on payback time.

Figure 6 2d k-means clustering 
Figure 7

a) k-means clustering b) clustering influenced by overshadowing from the surrounding

Table 1 BIPV design rules old of maximum average payback time is reached. The result is better clustering of BIPV panels as well as decreased computational time (Fig. 7).

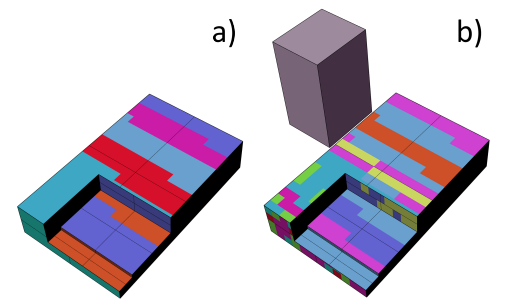

Case study. The methods were tested on number of buildings with different typology and use conditions. One of those case studies was MPREIS building located in Tirol, Austria. The building is a warehouse for storing frozen food. Due to this purpose it has an interesting electricity demand with almost constant yearly profile. The recorded real hourly power demand data obtained from the building's operatives were used for the analysis. The analysis were performed using following criteria:

- Electricity purchase price $=0.115 € / \mathrm{kWh}$

- Feed-in tariff $=0.76 € / \mathrm{kWh}$

- PV cost on the facades $=175,8 € / \mathrm{m} 2$

- PV cost on the roof $=205.4 € / \mathrm{m} 2$

- $100 \%$ of the façade area can be used for PV, $80 \%$ of the roof area can be used for PV

- PV system for facade and roof glass / cell / glass, open rack

- PV module, poly-Si, efficiency $16 \%$

- Invertor efficiency $95 \%$

The analysis (figure 8) show the distribution of PV panels and their investment return. On the roof the investment return is 15 years while on the facade up to 28 years for the total area coverage. However, as it seen on the graphs, it actually makes sense to only install panels with less then 18 years of payback time, otherwise the contribution to the energy production with regards to the building demand profile is insignificant.

\section{CONCLUSION}

The individual urban location is key when assessing the solar potential for BIPV, especially on façades. Therefore, the method indicating optimal placements for PV modules with best yield performance on the building surface were set up and investigated. The tools for improvement to optimize the PV placement for minimizing the deviation between the profile of energy demand and profile of PV production were created and tested with positive results. Based on the performed studies were also set up some simple rule of thumb guidelines that can be used during the planning as fast decision makers (Table 1). The next step would be to investigate multicriteria optimization of a building design; for example the windows versus BIPV placement would be contradictory in terms of affecting the building's energy demand and optimal lighting condition.

The tools based on the presented methods were created for the Rhino/Grasshopper environment [2]. The VITALITY library can be connected to other existingtools, e.g. DIVA for the calculation of hourly solar radiationand ARCHSIM for getting the energy demand profile of thebuilding.

\begin{tabular}{|c|l|l|}
\hline Rules & \multicolumn{1}{|c|}{ Planning objectives } & \multicolumn{1}{|c|}{ Actions } \\
\hline 1 & Highest yield & $\begin{array}{l}\text { Roof mounted system, } \\
\text { oriented south, inclination } 30^{\circ}, \\
\text { full coverage }\end{array}$ \\
\hline 2 & $\begin{array}{l}\text { High yield, balanced daily } \\
\text { energy yield }\end{array}$ & $\begin{array}{l}\text { Roof mounted system, } \\
\text { oriented south or east-west, } \\
\text { inclination less than } 20^{\circ}, \text { full } \\
\text { coverage }\end{array}$ \\
\hline 3 & $\begin{array}{l}\text { High yield in the morning and } \\
\text { evening }\end{array}$ & $\begin{array}{l}\text { Roof mounted system, } \\
\text { oriented east-west, } \\
\text { inclination more than 30 }\end{array}$ \\
\hline 4 & $\begin{array}{l}\text { High yield in the morning or } \\
\text { evening }\end{array}$ & $\begin{array}{l}\text { Roof mounted system, } \\
\text { oriented east or west, } \\
\text { inclination more than 30 }\end{array}$ \\
\hline 5 & $\begin{array}{l}\text { Yield in the early morning and } \\
\text { late evening }\end{array}$ & $\begin{array}{l}\text { Facade integrated system, } \\
\text { orientated east-west }\end{array}$ \\
\hline 6 & $\begin{array}{l}\text { Balanced yield with high } \\
\text { production in transition period }\end{array}$ & $\begin{array}{l}\text { Facade integrated system, } \\
\text { orientated south }\end{array}$ \\
\hline 7 & High balanced yearly yield & $\begin{array}{l}\text { Combination of roof mounted } \\
\text { and façade integrated system }\end{array}$ \\
\hline 8 & $\begin{array}{l}\text { Economic design } \\
\text { 1. Cover the full roof 2. Cover } \\
\text { upper floors of the south } \\
\text { facade 3. Cover upper floors of } \\
\text { the east and west facade }\end{array}$ \\
\hline
\end{tabular}



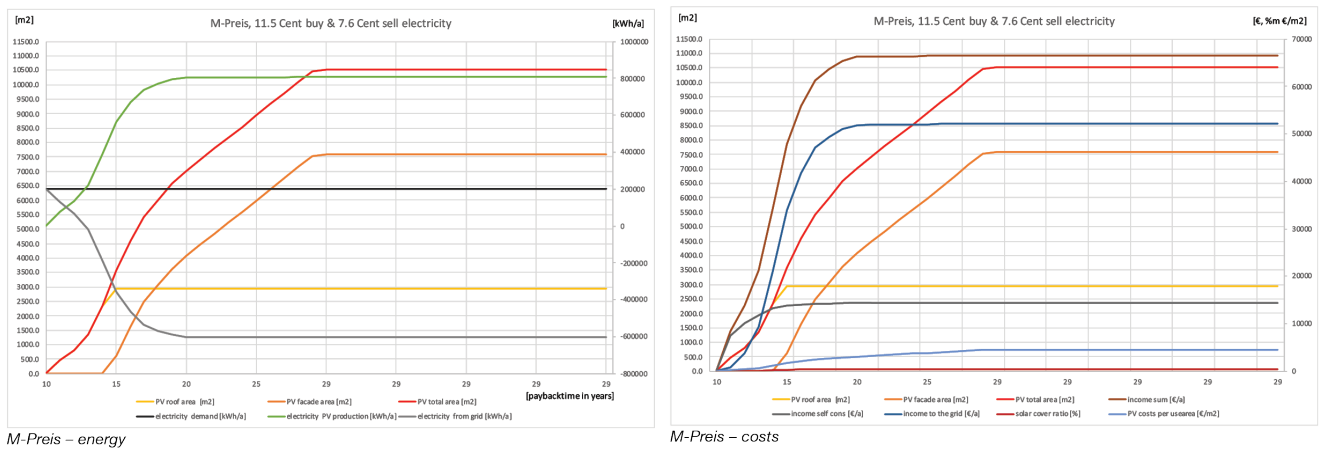

Figure 8

BIPV evaluation of MPREIS warehouse, Tirol, Austria

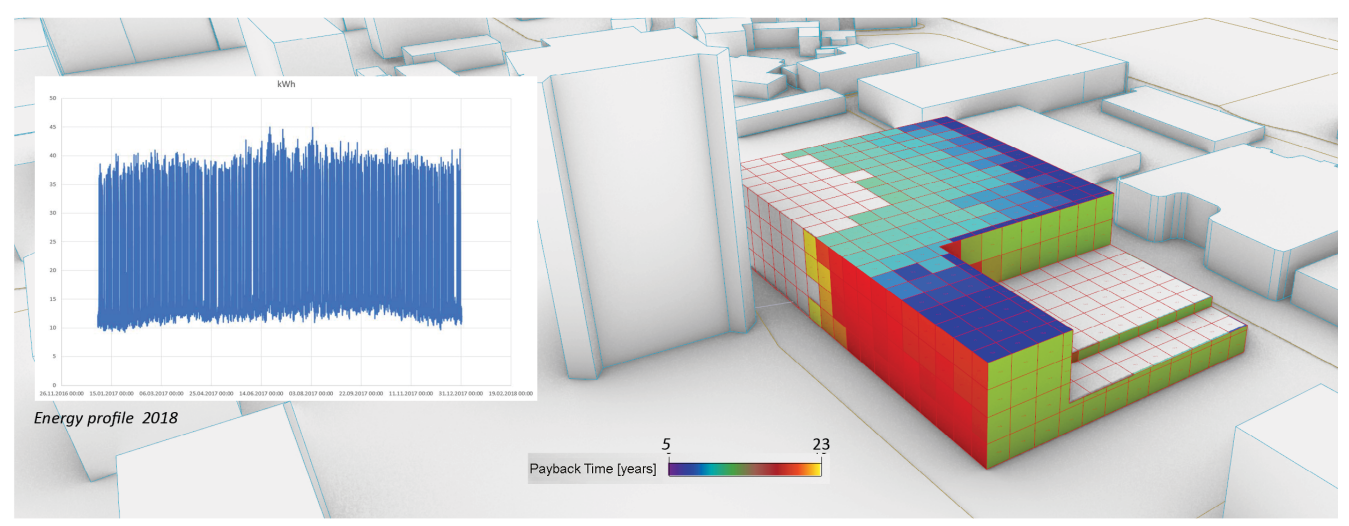

\section{REFERENCES}

Kaftan, M. 2016, 'Exploration of Optimal Solutions in Architecture', International Journal of Contemporary Architecture "The New ARCH", 3, pp. 20-27

Perez, M. J., Fthenakis, M., Kim, H.C. and Pereira, A.O. 2012, 'Façade-integrated photovoltaics: a life cycle and performance assessment case study', Progress in Photovoltaics, 20, p. 975-990

Ritzen, M.J., Vroon, Z.A.E.P., Rovers, R. and Geurts, C.P.W. 2017, 'Comparative performance assessment of a non-ventilated and ventilated BIPV rooftop configurations in the Netherlands', Solar Energy, 146, p. 389-400

Steinbach, M., Ertöz, L. and Kumar, V. 2004, 'The Challenges of Clustering High Dimensional Data', in Wille, L.T. (eds) 2004, New Directions in Statistical Physics, Springer, Berlin, pp. 273-309
[1] https://eur-lex.europa.eu/homepage.html

[2] https://www.food4rhino.com/app/vitality 